\title{
Multidisciplinary applications of complex networks modeling, simulation, visualization, and analysis
}

\author{
Carlos Gershenson ${ }^{1 *}$ and Muaz A Niazi ${ }^{2}$
}

\footnotetext{
*Correspondence: cgg@unam.mx ${ }^{1}$ Universidad Nacional Autónoma de México, A.P. 20-726, 01000 México city, D.F, México Full list of author information is available at the end of the article
}

\section{Complex systems and networks}

Complex Adaptive Systems (CAS) or complex systems are characterized by the interactions between their numerous elements. The word 'complex' comes from the Latin plexus which means entwined. In other words, it is difficult to correlate global properties of complex systems with the properties of the individual constituent components. This is primarily because the interactions between these individual elements partly determine the future states of the system (Gershenson 2013). If these interactions are not included in the developed models, the models would not be an accurate reflection of the modelled phenomenon.

While numerous techniques and frameworks for modeling complex systems have previously been devised (Niazi 2011), clearly one of the most explicit and intuitive methodology is the modeling of interactions using networks (Niazi and Hussain 2012). Networks consist of nodes or vertices, which can be used to represent elements, and links or edges, which usually represent interactions or relations between the elements. In this context, networks represent the structure of complex systems; how elements interact. However, networks can also be used to represent the dynamics or function of complex systems, e.g. considering nodes as states and links as transitions. Thus, the same analysis can be applied to the structure and the function of networks. Understanding the relationship between structure and function is one of the major open questions across sciences, which can also be posed using networks: how do changes in the structural network affect the state network? (Boccaletti et al. 2006; Gershenson 2012). For example, what will be the effect of knocking out a gene in the behavior of a cell? Several systems change their structure over time, and their properties can be modelled with temporal networks (Holme and Saramäki 2012). Likewise, there are several instances when the structural changes are triggered by the state of the network, as has been studied in adaptive networks (Gross and Sayama 2009).

With not much more than a decade of network research, there are already numerous applications of networks in diverse areas, such as epidemiology (Colizza et al. 2007; Christakis and Fowler 2007; Pastor-Satorras and Vespignani 2001), human mobility (Gonzalez et al. 2008), social networks (Huberman et al. 2009; Niazi and Hussain 2011), artificial life (Gershenson and Prokopenko 2011), life sciences (Bullmore and Sporns 2009; Gershenson 2004; Guimera and Nunes Amaral 2005; Montoya et al. 2006), theory of

(O2013 Gershenson and Niazi; licensee Springer. This is an Open Access article distributed under the terms of the Creative Commons Attribution License (http://creativecommons.org/licenses/by/2.0), which permits unrestricted use, distribution, and reproduction in any medium, provided the original work is properly cited. 
computation (Gershenson 2010), and engineering (Broder et al. 2000; Helbing et al. 2006; Niazi and Hussain 2013a, 2013b; Prehofer and Bettstetter 2005), just to mention a few. Some other examples of research in the area of networks include (Albert and Barabási 2002; Barabási 2002; Barrat et al. 2008; Caldarelli 2007; Motter and Albert 2012; Newman 2003; Newman et al. 2006; Newman 2010; Strogatz 2001).

\section{Papers in the special issue}

In the first paper "Penetration capacity of the wood-decay fungus Physisporinus vitreus", the authors Matthias Jörg Fuhr, Mark Schubert, Chris Stührk, Francis WMR Schwarze and Hans Jürg Herrmann propose the study of bioincising by means of a model considering many factors affecting the growth and effects of P. vitreus in Norway spruce (Fuhr et al. 2013).

In the next paper, "Information theoretical methods for complex network structure assessment", the authors Enrique Hernández-Lemus and Jesús M Siqueiros-García duscuss how information theory can provide effective means for structural assessment in domains such as biological and social network analysis (Hernandez-Lemus and SiqueirosGarcia 2013).

In the paper "Information and Phase Transitions in Socio-Economic Systems", the authors Terry Bossomaier, Lionel Barnett and Michael Harré present an interesting study on the role of information-based measures in detecting and analysing phase transitions. They contend that phase transitions have general features and can be detected in diverse systems using information theory (Bossomaier et al. 2013).

In the next paper, "Clustering Datasets by Complex Networks Analysis" by Giuliano Armano and Marco Alberto Javarone, the authors propose a method based on complex network analysis which allows clustering on multidimensional datasets (Armano and Javarone 2013).

In the article "PyCX: a Python-based simulation code repository for complex systems education", Hiroki Sayama introduces PyCX, an online python-based code repository of simple, crude but easy-to-understand sample codes for various complex systems simulation, including iterative maps, cellular automata, dynamical networks and agent-based models (Sayama 2013).

In the article "Segregation mechanisms of tissue cells: from experimental data to models", Előd Méhes and Tamás Vicsek present a review of pattern formation by segregation of tissue cells. In addition, the authors present experimental observations, including some new results on various aspects of two and three dimensional segregation events and then summarize various computational modeling approaches (Méhes and Vicsek 2013).

In the final article, "Large-scale global optimization through consensus of opinions over complex networks" by Omid Askari-Sichani and Mahdi Jalili, the authors present a model based on consensus of opinions among agents interacting over a complex networked structure for a large-scale task optimization. They demonstrate how agents can solve such tasks using collaborations and forming consensus of opinions (Askari-Sichani and Jalili 2013).

\section{Acknowledgements}

The editors would like to acknowledge the continual support provided by Leslie De La Vega and Natalie Shon from SpringerOpen during the production of the special issue. C.G. was partially supported by SNI membership 47907 of CONACYT, Mexico. 
Author details

${ }^{1}$ Universidad Nacional Autónoma de México, A.P. 20-726, 01000 México city, D.F, México. ${ }^{2}$ Bahria University, Shangrila Road, E-8, Islamabad, Pakistan.

Received: 30 August 2013 Accepted: 30 August 2013

Published: 08 Nov 2013

References

Albert R, Barabási AL: Statistical mechanics of complex networks. Rev Mod Phys 2002, 74:47-97. [http://link.aps.org/ doi/10.1103/RevModPhys.74.47]

Armano G, Javarone MA: Clustering datasets by complex networks analysis. Complex Adaptive Syst Model 2013, $1: 1-10$.

Askari-Sichani O, Jalili M: Large-scale global optimization through consensus of opinions over complex networks. Complex Adaptive Syst Model 2013, 1:11.

Barabási AL: Linked: The New Science of Networks. Cambridge, MA, USA: Perseus; 2002. [http://barabasilab.com/ LinkedBook/].

Barrat A, Barthelemy M, Vespignani A: Dynamical processes in complex networks. Cambridge, UK: Cambridge University Press; 2008.

Boccaletti S, Latora V, Moreno Y, Chavez M, Hwang DU: Complex networks: Structure and dynamics. Phys Rep 2006, 424(4-5):175-308. [http://dx.doi.org/10.1016/j.physrep.2005.10.009]

Bossomaier T, Harré M, et al.: Information and phase transitions in socio-economic systems. Complex Adaptive Syst Model 2013, 1:9.

Broder A, Kumar R, Maghoul F, Raghavan P, Rajagopalan S, Stata R, Tomkins A, Wiener J: Graph structure in the web. Comput Netw 2000, 33(1-6):309-320. [http://www.sciencedirect.com/science/article/pii/S1389128600000839]

Bullmore $\mathrm{E}$, Sporns $\mathrm{O}$ : Complex brain networks: graph theoretical analysis of structural and functional systems. Nat Rev Neurosci 2009, 10(3):186-198. [http://dx.doi.org/10.1038/nrn2575]

Caldarelli G: Scale-Free Networks. Oxford, UK: Oxford University Press; 2007.

Christakis NA, Fowler JH: The spread of obesity in a large social network over 32 years. N Engl J Med 2007, 357(4):370-379. [http://www.nejm.org/doi/full/10.1056/NEJMsa066082]. [PMID: 17652652]

Colizza V, Barrat A, Barthelemy M, Valleron AJ, Vespignani A: Modeling the worldwide spread of pandemic influenza: baseline case and containment interventions. PLoS Med 2007, 4:e13. [http://dx.doi.org/10.1371/journal.pmed. 0040013]

Fuhr MJ, Schubert M, Stührk C, Schwarze FW, Herrmann HJ: Penetration capacity of the wood-decay fungus Physisporinus vitreus. Complex Adaptive Syst Model 2013, 1:1-15.

Gershenson C: Introduction to Random Boolean Networks. In Workshop and Tutorial Proceedings, Ninth International Conference on the Simulation and Synthesis of Living Systems (ALife IX). Edited by Bedau M, Husbands P, Hutton T, Kumar S, Suzuki H. Boston: MA; 2004:160-173. [http://arxiv.org/abs/nlin.AO/0408006]

Gershenson, C: Computing networks: a general framework to contrast neural and swarm cognitions. Paladyn, J Behav Robot 2010, 1(2):147-153. [http://dx.doi.org/10.2478/s13230-010-0015-z]

Gershenson C: Guiding the self-organization of random boolean networks. Theory Biosci 2012, 131(3):181-191. [http://arxiv.org/abs/1005.5733]

Gershenson, C: The implications of interactions for science and philosophy. Early view. Foundations Sci 2013. [http://arxiv.org/abs/1105.2827]

Gershenson C, Prokopenko M: Complex networks. ArtifLife 2011, 17(4):259-261. [http://arxiv.org/abs/1 104.5538]

Gonzalez MC, Hidalgo CA, Barabasi AL: Understanding individual human mobility patterns. Nature 2008, 453(7196):779-782. [http://dx.doi.org/10.1038/nature06958]

Gross T, Sayama H (Eds): Adaptive networks: Theory, Models and Applications. Understanding Complex Systems, Berlin Heidelberg: Springer; 2009. [http://dx.doi.org/10.1007/978-3-642-01284-6]

Guimera R, Nunes Amaral LA: Functional cartography of complex metabolic networks. Nature 2005, 433(7028):895-900. [http://dx.doi.org/10.1038/nature03288]

Helbing D, Armbruster D, Mikhailov AS, Lefeber E: Information and material flows in complex networks. Physica A: Stat Mech App/ 2006, 363:11-16. [http://www.sciencedirect.com/science/article/pii/S0378437106000835] [<ce:title>Information and Material Flows in Complex Networks</ce:title><xocs:full-name>Information and Material Flows in Complex Networks</xocs:full-name>]

Hernandez-Lemus E, Siqueiros-Garcia J: Information theoretical methods for complex network structure reconstruction. Complex Adaptive Syst Model 2013, 1:8. [http://www.casmodeling.com/content/1/1/8]

Holme P, Saramäki J: Temporal networks. Phys Rep 2012, 519(3):97-125. [http://arxiv.org/abs/1108.1780]

Huberman BA, Romero DM, Wu F: Social networks that matter: twitter under the microscope. First Monday 2009, 14:1-5. [http://www.hpl.hp.com/research/scl/papers/twitter/twitter.pdf]

Méhes E, Vicsek T: Segregation mechanisms of tissue cells: from experimental data to models. Complex Adaptive Syst Model 2013, 1:4.

Montoya J, Pimm SL, Solé RV: Ecological networks and their fragility. Nature 2006, 442(7100):259-264. [http://dx.doi. org/10.1038/nature04927]

Motter AE, Albert R: Networks in motion. Phys Today 2012, 65(4):43-48. [http://dx.doi.org/10.1063/PT.3.1518]

Newman MEJ: The structure and function of complex networks. SIAM Review 2003, 45:167-256. [http://arxiv.org/abs/ cond-mat/0303516]

Newman M, Barabási AL, Watts DJ (Eds): The Structure and Dynamics of Networks. Princeton Studies in Complexity, Princeton, NJ, USA: Princeton University Press; 2006.

Newman M: Networks: An Introduction. Oxford, UK: Oxford University Press; 2010. 
Niazi MA: Towards a novel unified framework for developing formal, network and validated agent-based simulation models of complex adaptive systems. PhD thesis. University of Stirling, Stirling, Scotland, UK 2011

Niazi MA, Hussain A: Social network analysis of trends in the consumer electronics domain. In consumer electronics (ICCE), 2011 IEEE international conference on. New York, USA: IEEE; 2011:219-220.

Niazi MA, Hussain A: Cognitive Agent-based Computing: Exploring Emergent Behavior in Complex Adaptive Systems using Agent-based Modeling and Complex Networks. Springer Dordrecht Netherlands: Springer-Verlag; 2012.

Niazi MA, Hussain A: Complex adaptive communication networks and environments: part 1. Simulation 2013a, 89(5):559-561.

Niazi MA, Hussain A: Complex adaptive communication networks and environments: part 2. Simulation 2013b, 89(7):787-789.

Pastor-Satorras R, Vespignani A: Epidemic spreading in scale-free networks. Phys Rev Lett 2001, 86:3200-3203. [http:// dx.doi.org//10.1103/PhysRevLett.86.3200]

Prehofer C, Bettstetter C: Self-organization in communication networks: principles and design paradigms. Commun Mag IEEE 2005, 43(7):78-85. [http://dx.doi.org/10.1109/MCOM.2005.1470824]

Sayama H: PyCX: a Python-based simulation code repository for complex systems education. Complex Adaptive Syst Model 2013, 1:1-10.

Strogatz SH: Exploring complex networks. Nature 2001, 410:268-276. [http://dx.doi.org/10.1038/35065725]

10.1186/2194-3206-1-17

Cite this article as: Gershenson and Niazi: Multidisciplinary applications of complex networks modeling, simulation, visualization, and analysis. Complex Adaptive Systems Modeling 2013, 1:17

Submit your manuscript to a SpringerOpen ${ }^{\circ}$ journal and benefit from:

- Convenient online submission

- Rigorous peer review

- Immediate publication on acceptance

- Open access: articles freely available online

- High visibility within the field

Retaining the copyright to your article

Submit your next manuscript at $\boldsymbol{\triangleright}$ springeropen.com 